\title{
AVALIAÇÃO DAS ESPÉCIES VEGETAIS UTILIZADAS NA ARBORIZAÇÃO EM CANTEIROS E PRAÇAS DE TUPARETAMA, PERNAMBUCO, NORDESTE DO BRASIL
}

\author{
EVALUATION OF PLANT SPECIES USED IN AFFORESTATION OF BEDS AND \\ SQUARES OF TUPARETAMA, PERNAMBUCO, NORTHEAST BRAZIL
}

Rafael Francisco Lopes Silva ${ }^{1}$, Jacyelle de Souza Rodrigues²${ }^{2}$, Maria de Fátima de Araújo Lucena ${ }^{3}$

\begin{abstract}
RESUMO
O aumento expressivo da expansão urbana traz consigo a preocupação em arborizar os espaços públicos, buscando respostas estéticas positivas para o ambiente e uma melhor qualidade de vida para a população. Este trabalho objetivou realizar uma avaliação das espécies vegetais utilizadas na arborização dos canteiros e praças do município de Tuparetama, Pernambuco. Foram percorridos aproximadamente $330 \mathrm{~m}$ de canteiros e $7.900 \mathrm{~m}^{2}$ de praças deste município, a fim de identificar as espécies vegetais arbustivas e arbóreas, ao tempo que contabilizava-se seus indivíduos. O material florido e/ou frutificado foi coletado e depositado no acervo do Herbário CSTR da Universidade Federal de Campina Grande (UFCG) e a identificação dos táxons foi feita através de literatura especializada. Foi avaliada a diversidade das espécies por meio do índice de diversidade de Shannon-Wiener e a frequência relativa das mesmas. Foram identificadas 40 espécies, distribuídas em 36 gêneros e 24 famílias. As famílias mais representativas foram Apocynaceae, Arecaceae e Fabaceae. $O$ hábito arbustivo superou o arbóreo quanto à riqueza e frequência, assim como as espécies exóticas sobre as nativas. $O$ índice de diversidade foi positivo, porém, o fato da prevalência de espécies exóticas é preocupante.
\end{abstract}

Palavras-chave: Levantamento florístico; Flora urbana; Semiárido; Planejamento urbano.

\section{ABSTRACT}

The expressive increase of urban expansion brings with it the concern to grow public spaces in order to obtain good aesthetic responses to the environment and a better quality of life for the population. This study aimed to evaluate the plant species used in the afforestation of the beds and squares of the municipality of Tuparetama, Pernambuco. Approximately $330 \mathrm{~m}$ of beds and $7,900 \mathrm{~m}^{2}$ of squares of this municipality were traversed, in order to identify the shrub species, and the trees, while counting their individuals. Flowering and/or fruiting material was collected and deposited in the CSTR Herbarium of the UFCG and the identification of the taxa was done through specialized literature. The species diversity was evaluated through the Shannon-Wiener diversity index and their relative frequency. Were identified 40 species, distributed in 36 genera and 24 families. The most representative families were Apocynaceae, Arecaceae and Fabaceae. The shrub habit outweighed the arboreal for richness and frequency, as did exotic species over native ones. The diversity index was positive, however, the fact of the prevalence of exotic species is worrisome.

Keywords: Floristic survey; Urban flora; Semiarid; Urban planning.

Recebido em 06.02.2017 e aceito em 23.03.2017

1 Graduando em Ciências Biológicas, Universidade Federal da Campina Grande, Centro de Saúde e Tecnologia Rural. Patos/PB E-mail: rafaeluacb@gmail.com

2 Graduanda em Ciências Biológicas, Universidade Federal da Campina Grande, Centro de Saúde e Tecnologia Rural. Patos/PB E-mail:jacyellerodrigues@gmail.com

3 Bióloga, Dra., Professora da Unidade Acadêmica de Ciências Biológicas da Universidade Federal de Campina Grande. Patos/PB E-mail: mfalucena@hotmail.com 


\section{INTRODUÇÃO}

Atualmente, observa-se um aumento expressivo na extensão territorial e consequentemente populacional dos centros urbanos, e com isso a preocupação em arborizar os espaços públicos de maneira a obter o menor prejuízo possível a este ambiente, tem sido mais frequentemente considerada. Essas áreas a serem arborizadas são tidas como espaços livres onde a vegetação predomina e é elemento fundamental (TOLEDO; SANTOS, 2008), que correspondem em geral a parques, jardins, praças ou canteiros.

As praças são áreas verdes de espaços públicos urbanos, cuja função é promover convivência sadia à população, oferecendo recreação e bem-estar ambiental, e também favorecer o acesso ao esporte e ao lazer, incentivando assim a inclusão social e expressão cultural (DANTAS; GOMES; PINHEIRO, 2016). As praças arborizadas promovem vários benefícios à população da cidade, como a possibilidade de conviver com diversas cores, texturas e formas, além de melhorar a qualidade de vida, através de melhorias climáticas, ambientais e psicológicas (DE ANGELIS; LOBODA, 2005; DANTAS; GOMES; PINHEIRO, 2016).

É nítida a empatia das pessoas para com esse tipo de ambiente, e por isso essa relação deve ser mantida e fortalecida pelos setores responsáveis. Para tal, é necessário que profissionais habilitados componham a gestão desses espaços, haja vista que a manutenção da integridade desses espaços e equilíbrio dessa flora urbana é indispensável. Sendo importante salientar como aspecto chave nesse processo, as espécies a serem utilizadas, as quais devem ser rigorosamente selecionadas.

A origem dessas espécies deve ser um critério sempre presente no ato da escolha das espécies que serão utilizadas, uma vez que o uso de plantas exóticas na arborização pode gerar problemas ambientais, na biodiversidade e na economia regional, enquanto espécies nativas proporcionam interessantes benefícios à população e a fauna residente (ZILLER; ZENNI; DECHOUM 2007).

Apesar de megadiverso floristicamente, o Brasil possui fortes contrastes em alguns de seus grandes centros urbanos e pequenos municípios, onde se evidencia muitas cidades desprovidas de áreas verdes e outras que estão entre as mais verdes nos rankings mundiais. João Pessoa, localizada no litoral do estado da Paraíba, é uma das mais verdes cidades do país e do mundo; Recife no litoral pernambucano tem aumentado consideravelmente o número de tetos verdes. Realidade essa, diferente da região semiárida desses mesmos estados, onde uma grande lacuna de conhecimento acerca da vegetação ocorrente nas cidades ainda é observada e os esforços dos órgãos públicos para que uma arborização de qualidade seja construída, são insuficientes (ALENCAR et al., 2014). 
Neste sentido, se faz extremamente importante, que estudos sobre a arborização das áreas verdes urbanas sejam desenvolvidos, uma vez que tais resultados poderão subsidiar propostas de melhorias para as cidades nesse aspecto.

Pensando nisso, foi objetivo deste trabalho avaliar as espécies vegetais arbustivoarbóreas utilizadas na arborização dos canteiros e praças do município de Tuparetama, sertão do estado de Pernambuco.

\section{MATERIAL E MÉTODOS}

\section{Área de estudo}

O município de Tuparetama (07ํ36'08"/ 37ํ18'41") localiza-se na mesorregião do Sertão e na microrregião do Pajeú, no estado de Pernambuco, apresentando clima do tipo BSh semiárido (ALVARES et al., 2013). Sua população estima-se em 8.149 habitantes (IBGE, 2016), com altitude média de 560m e área de $231 \mathrm{~km}^{2}$, estando totalmente inserida na bacia hidrográfica do Rio Pajeú, com relevo ondulado a suavemente ondulado e vegetação de caatinga predominantemente hiperxerófila (BELTRÃO et al., 2005). Suas praças e canteiros estão distribuídos desde os bairros periféricos até o centro da cidade.

Foram percorridos aproximadamente $330 \mathrm{~m}$ de canteiros e $7.900 \mathrm{~m}^{2}$ de praças deste município, a fim de identificar as espécies vegetais arbustivas e arbóreas utilizadas em seu paisagismo, ao tempo que se contabilizava seus indivíduos.

\section{Processamento dos dados}

O material florido e/ou frutificado foi coletado e preparado para ser depositado no acervo do Herbário do Centro de Saúde e Tecnologia Rural da Universidade Federal de Campina Grande, de acordo com a metodologia apresentada pelo IBGE (2012). A identificação dos táxons foi feita através de literatura especializada e principalmente guias de imagens.

A lista florística está organizada em ordem alfabética de família e o sistema de classificação utilizado foi o APG IV (2016). A grafia dos nomes das espécies e seus respectivos autores estão de acordo com o The Plant List e com a lista de espécies da flora do Brasil (BFG, 2015), assim como sua origem, onde aquelas que aparecem como cultivadas ou naturalizadas foram consideradas exóticas.

Foi avaliada a diversidade das espécies por meio do índice de diversidade de Shannon-Wiener (SHANNON; WEAVER, 1964), $H^{\prime}=-\Sigma p_{i} \log p_{i}$ e a frequência relativa das 
mesmas, a qual foi calculada através da razão entre o número de indivíduos da espécie e o número total de indivíduos, multiplicada por 100, assim como feito também por Camaño et al. (2015). Para isso, os dados foram plotados e calculados em planilha do software Microsoft Excel.

\section{RESULTADOS E DISCUSSÃO}

Foram identificadas 40 espécies (Tabela 1), distribuídas em 36 gêneros e 24 famílias. Dessas espécies, 38 são angiospermas e duas gimnospermas. Os indivíduos contabilizados totalizaram 911, dos quais 280 são árvores e 629 arbustos.

Além de mais abundante, o hábito arbustivo também apresentou maior riqueza, com 26 espécies (65\%). Os arbustos geralmente apresentam um menor porte e calibre de raízes em comparação com as árvores, o que pode favorecê-los no momento da seleção das espécies, pois essas características influenciarão no grau de interferência em redes elétricas, calçadas e encanamentos. Todavia, normalmente por possuírem uma maior área foliar, as árvores proporcionam mais sombra e diminuem mais eficazmente a sensação térmica.

As famílias mais representativas foram Apocynaceae, Arecaceae e Fabaceae, com quatro espécies cada, seguidas por Bignoniaceae com três espécies e Anacardiaceae, Annonaceae, Cactaceae, Rubiaceae e Rutaceae com duas espécies cada. Para as demais famílias registrou-se apenas uma espécie.

Apocynaceae tem uma grande variação de plantas ornamentais, com flores muito vistosas, assim como Fabaceae, que é uma das maiores famílias botânicas, sendo a mais expressiva da Caatinga. A família Arecaceae é representada pelas palmeiras, também muito valorizadas esteticamente. Essas são muito utilizadas no paisagismo de praças e outros espaços públicos e privados.

Ixora coccinea foi a espécie mais comum, com 38,86\% dos indivíduos catalogados. Essa espécie é extremamente utilizada na ornamentação de praças, canteiros e outros espaços públicos. Plumbago auriculata representa 11,75\% dos indivíduos e Azadirachta indica foi a terceira espécie mais frequente, com 10,21\%, que apesar de também expressiva, sua frequência está dentro da recomendação de alguns autores, de que os indivíduos por espécie não ultrapassem 10 a 15\% da arborização urbana (MILANO; DALCIN, 2000). Entretanto, na arborização geral da cidade essa espécie (nim) representa a maciça prevalência, assim como sua alta expressividade é verificada em outras cidades do Sertão nordestino, como é o caso de São João do rio do peixe - PB (ALENCAR et al., 2014), Patos - PB (LUCENA et al., 2015) e Serra Talhada - PE (LUNDGREN; SILVA; ALMEIDA, 2013). 
Tabela 1. Lista florística das espécies arbustivo-arbóreas utilizadas na arborização dos canteiros e praças do município de Tuparetama, Sertão pernambucano, em ordem alfabética de família, seguido do nome popular, hábito (arb - arbusto; arv - árvore), origem, frequência absoluta (FA) e frequência relativa (FR) em \%

Table 1. Floristic list of tree and shrub species used in the afforestation of the Tuparetama municipality, in the alphabetical order of the family, followed by the popular name, habit (arb-bush, arvtree), origin, absolute frequency (FA) and relative frequency (FR) in \%

\begin{tabular}{|c|c|c|c|c|c|c|}
\hline Família & Espécie & Nome popular & Hábito & Origem & FA & $\mathrm{FR}(\%)$ \\
\hline \multirow[b]{2}{*}{ Anacardiaceae } & Mangifera indica L. & Mangueira & Arv. & Exótica & 11 & 1,21 \\
\hline & Anacardium occidentale $\mathrm{L}$. & Cajueiro & Arv. & Exótica & 01 & 0,11 \\
\hline \multirow[b]{2}{*}{ Annonaceae } & Annona muricata L. & Graviola & Arv. & Exótica & 03 & 0,33 \\
\hline & Annona squamosa L. & Pinha & Arb. & Exótica & 01 & 0,11 \\
\hline \multirow{4}{*}{ Apocynaceae } & Nerium oleander $\mathrm{L}$. & Espirradeira & Arb. & Exótica & 23 & 2,52 \\
\hline & Plumeria pudica Jacq. & Jasmim manga & Arb. & Exótica & 01 & 0,11 \\
\hline & Plumeria rubra L. & $\begin{array}{c}--- \\
-\end{array}$ & Arb. & Exótica & 02 & 0,22 \\
\hline & Thevetia peruviana & Chapéu de & Arb. & Nativa & 01 & 0,11 \\
\hline Araliaceae & Schefflera arboricola (Hayata) Merr & --- & Arb. & Exótica & 03 & 0,33 \\
\hline Araucariaceae & Araucaria heterophylla (Salisb.) Franco & ---- & Arv. & Exótica & 05 & 0,55 \\
\hline \multirow{4}{*}{ Arecaceae } & Veitchia sp. & $-\cdots$ & Arv. & Exótica & 05 & 0,55 \\
\hline & Roystonea oleracea (Jacq.) O.F.) & \multirow{2}{*}{ Palmeira imperial } & Arv. & Exótica & 36 & 3,95 \\
\hline & Arenga sp. & & Arv. & Exótica & 03 & 0,33 \\
\hline & Pinanga sp. & $-\cdots$ & Arb. & Exótica & 02 & 0,21 \\
\hline Begoniaceae & Begonia sp. & $-\cdots$ & Arb. & Exótica & 05 & 0,55 \\
\hline \multirow{3}{*}{ Bignoniaceae } & Handroantus impetiginosus (Mart. ex DC.) & Ipê rosa/Pau & Arv. & Nativa & 24 & 2,63 \\
\hline & Handroantus chrysotrichus (Mart. ex DC.) Mattos & Ipê amarelo & Arb. & Nativa & 04 & 0,44 \\
\hline & Tecoma stans & Ipezinho amarelo & Arb. & Exótica & 01 & 0,11 \\
\hline \multirow{2}{*}{ Cactaceae } & Cereus jamacaru DC. & Mandacaru & Arb. & Nativa & 02 & 0,22 \\
\hline & Hylocereus undatus (Haw.) Britton \& Rose & $-\cdots$ & Arb. & Exótica & 01 & 0,11 \\
\hline Caricaceae & Carica papaya L. & Mamoeiro & Arb. & Exótica & 01 & 0,11 \\
\hline Casuarinaceae & Casuarina equisetifolia $\mathrm{L}$. & $-\cdots$ & Arv. & Exótica & 30 & 3,29 \\
\hline Cupressaceae & Platycladus orientalis (L.) Franco & $-\cdots$ & Arb. & Exótica & 01 & 0,11 \\
\hline Euphorbiaceae & Jatropha mollissima (Pohl) Baill. & Pinhão & Arb. & Nativa & 03 & 0,33 \\
\hline \multirow{4}{*}{ Fabaceae } & Bauhinia cheilantha L. & Pata de vaca & Arb. & Nativa & 17 & 1,87 \\
\hline & Bauhinia variegata $\mathrm{L}$. & Coração & Arb. & Nativa & 05 & 0,55 \\
\hline & Erythrina variegata $\mathrm{L}$. & --- & Arv. & Exótica & 01 & 0,11 \\
\hline & Senna siamea (Lam.) H.S.Irwin \& Barneby & Acácia & Arv. & Exótica & 03 & 0,33 \\
\hline Malvaceae & Hibiscus rosa-sinensis L. & Papoula & Arb. & Exótica & 01 & 0,11 \\
\hline Meliaceae & Azadirachta indica A. Juss & $\mathrm{Nim}$ & Arv. & Exótica & 93 & 10,21 \\
\hline Moraceae & Ficus benjamina L. & Ficus & Arv. & Exótica & 64 & 7,02 \\
\hline Myrtaceae & Syzygium cumini & Azeitona & Arv. & Exótica & 01 & 0,11 \\
\hline Nyctaginaceae & Bougainvillea spectabilis & Buganville & Arb. & Nativa & 10 & 1,10 \\
\hline Plumbaginaceae & Plubago auriculata Lam. & $-\cdots$ & Arb. & Exótica & 10 & 11,75 \\
\hline \multirow{2}{*}{ Rubiaceae } & Ixora coccinea L. & $-\cdots$ & Arb. & Exótica & 35 & 38,86 \\
\hline & Morinda citrifolia $L$. & Noni & Arb. & Exótica & 01 & 0,11 \\
\hline \multirow[b]{2}{*}{ Rutaceae } & Citrus $x$ aurantium $\mathrm{L}$. & Laranjeira & Arb. & Exótica & 02 & 0,22 \\
\hline & Murraya sp. & --- & Arb & Exótica & 05 & 0,55 \\
\hline Verbenaceae & Duranta erecta L. & Pingo de ouro & Arb. & Exótica & 77 & 8,45 \\
\hline Vitaceae & Leea rubra Blume ex Spreng. & $-\cdots$ & Arb. & Exótica & 01 & 0,11 \\
\hline
\end{tabular}

Ficus benjamina foi a quinta espécie mais abundante, com 7,02\% dos indivíduos, número também dentro do limite recomendável. Trabalhos como os de Rodolfo Júnior et al. (2008) em Pombal - PB, Batista et al. (2013) em Remígio - PB, Lundgren, Silva e Almeida (2013) em Serra Talhada - PE, Camaño et al. (2015) em Santa Helena - PB e Bezerra, Costa 
e Silva (2016) em Monteiro - PB evidenciam a dominância deste táxon na arborização dessas cidades interioranas do bioma caatinga. Nesta problemática do plantio excessivo de apenas uma ou duas espécies na arborização de uma cidade, sendo elas exóticas ou não, alerta-se para diversos inconvenientes ambientais, entre estes: a baixa diversidade de alimentos para pássaros, abelhas e borboletas; monotonia visual estética na paisagem da cidade, possibilidade de pragas a infestar e devastar de imediato todos os indivíduos da espécie, além da desvalorização do nosso patrimônio natural de plantas e animais.

Para Bezerra, Costa e Silva (2016) a espécie F. benjamina é causadora de muitos problemas no perímetro urbano, sendo danosa a outras espécies, levando ao seu tombamento e rachaduras em calçamentos e construções. Esses autores afirmam ainda, que ela está sendo amplamente utilizada na arborização, principalmente devido ao seu rápido crescimento e desenvolvimento nas regiões áridas.

No caso do nim, estudos recentes tem revelado um alto potencial em seus princípios ativos, podendo todas as suas partes serem utilizadas. Seu óleo essencial tem sido descrito com grande poder antifúngico, antibacteriano, antiparasitário e inseticida.

Percebe-se uma preferência por parte das prefeituras e da população, o plantio de espécies visando seu rápido crescimento e potencial de sobreamento, como é o caso do ficus e do nim ( $F$. benjamina e $A$. indica), que se desenvolvem rapidamente, mesmo em condições de escassez hídrica. A arborização geral da cidade é caracterizada pela prevalência dessas mesmas espécies.

É frequente que na arborização urbana, poucas espécies representem a maior parte da população (SILVA, 2000). Porém, se faz extremamente necessário que se consolide ao máximo a diversidade de espécies nesses ambientes, uma vez que a monocultura e baixa diversidade podem levar a arborização a enfrentar problemas como ataques de fito-patógenos e pragas.

O índice de diversidade obtido para este trabalho foi de 2,26, mais alto que o verificado por Dantas, Gomes e Pinheiro (2016), na composição florística da praça Floriano Peixoto em Macapá - AP que foi de 0,98 e mais baixo que o encontrado por Carvalho Maria, Biondi e Brobowski $(2016)(3,34)$ nas vias públicas de Itanhaém - SP, os quais afirmam que o índice acima de 3 é considerado alto. Levando em consideração a não inclusão neste trabalho, de ervas e subarbustos, o índice encontrado para os canteiros e praças de Tuparetama indicam uma considerável diversidade de espécies.

Por razões estéticas e fitossanitárias, deve-se estabelecer o número e a proporção para cada espécie em relação ao total de árvores plantadas (MILANO; DALCIN, 2000).

A baixa diversidade de espécies pode levar à deterioração fitossanitária e de acordo com Sousa et al. (2014), o manejo fitossanitário adequado das árvores é fundamental para a 
prevenção de problemas desse tipo. Em aspectos gerais, as espécies catalogadas nesse trabalho apresentaram boas condições fitossanitárias, onde nenhuma possuía infestação de cupins ou qualquer outro tipo de ataque por invertebrados, nem troncos ocos. Também se pode afirmar, que os canteiros e praças analisados apresentam boa qualidade estética e estrutural.

Pode-se destacar, que sete espécies frutíferas (Anacardium occidentale, Annona muricata, Annona squamosa, Carica papaya., Citrus $x$ aurantium, Mangifera indica, Syzigium cumini) estão presentes na arborização desses canteiros e praças, porém, segundo Milano e Dalcin (2000) as condições viárias urbanas não constituem meio adequado ao processo produtivo de frutíferas, visto que seus frutos maduros que caem e permanecem no local, estão sujeitos a sujeiras e servem de alimento para vetores de doenças. Mas, sob o ponto de vista ecológico e ambiental, o uso de plantas frutíferas nativas na arborização é importante, pois propicia o fornecimento de recursos a fauna residente.

Quanto à presença de espécies tóxicas na arborização destacam-se Nerium oleander, Plumeria rubra e Thevetia peruviana, as quais já foram citadas por Souza et al., (2011) como detentoras de alto potencial toxicológico. Espécies tóxicas acabam sendo utilizadas na arborização das cidades e a população geralmente desconhece as ações que podem ser desencadeadas por essas plantas.

Nota-se, que a maioria dos táxons utilizados nos canteiros e praças da cidade de Tuparetama são exóticos (80\%), fato que pode ser explicado pela maior disponibilidade e mais fácil acesso a espécies com grande potencial para ornamentação e que ampliam as opções de aromas e floradas. Embora alguns estudos apontem a prevalência de espécies exóticas nas áreas verdes públicas, as plantas nativas devem ser sempre consideradas para compor a arborização urbana.

A principal causa de introdução intencional de espécies exóticas no país é seu uso ornamental (ZILLER; ZENNI; DECHOUM 2007). Sua utilização e predominância no paisagismo e arborização urbana ainda é bastante comum em diversas cidades brasileiras (BATISTA et al., 2013; LUNDGREN; SILVA; ALMEIDA, 2013; SOUSA et al., 2014; CAMAÑO et al., 2015; LUCENA et al., 2015; BASTOS et al. 2016; BEZERRA; COSTA; SILVA, 2016; DANTAS; GOMES; PINHEIRO, 2016; PERIOTTO et al., 2016).

Algumas características podem ser avaliadas durante a seleção das espécies para o plantio em áreas urbanas, como a tolerância a poluentes e às baixas condições de aeração do solo, crescimento e de longevidade, tamanho e coloração das flores e frutos, assim como a época e duração do florescimento e frutificação (MARTO et al., 2006).

Assim como servem de facilitadoras para dispersão de espécies exóticas que trazem impactos à diversidade biológica, as áreas urbanas também podem ter efeito benéfico através do plantio de espécies nativas da região, as quais podem contribuir para a restauração da 
resiliência dessas áreas naturais e a melhoria da riqueza de espécies e da diversidade biológica em escala regional, principalmente quando disseminadas por aves (ZILLER; ZENNI; DECHOUM, 2007).

A Caatinga por possuir diversas espécies com alto potencial ornamental e de sombreamento, como: Anadenanthera colubrina (Vell.) Brenan (angico), Aspidosperma pyrifolium Mart. (pereiro), Bauhinia cheilantha (Bong.) Steud. (mororó/pata-de-vaca), Handroanthus impetiginosus (Mart. ex DC.) Mattos (ipê-rosa/pau-d'arco), Libidibia ferrea (Mart. ex Tul.) L.P.Queiroz (pau-ferro), Myracrodruon urundeuva Allemão (aroeira), Poincianella pyramidalis (Tul.) (catingueira), Pseudobombax marginatum (A.St.-Hil.) A. Robyns (embiratanha), e Vellozia plicata Mart. (canela-de-ema). Sendo assim, as recomendamos para que possam ser utilizadas na arborização, levando sempre em consideração as características do local a serem utilizadas.

À medida que a flora nativa e a fisionomia natural da região são lembradas nos processos paisagísticos da arborização da cidade, pode-se possibilitar uma nova visão dos espaços verdes no perímetro urbano por parte da população, o que contribuirá para uma reavaliação dessas pessoas, acerca da comunicação cidade-meio-ambiente.

\section{CONCLUSÕES}

Os equívocos na implementação da arborização, junto ao pouco interesse dos órgãos responsáveis por isso, levam a um planejamento urbano deficiente.

Uma melhor participação de espécies nativas na arborização da cidade é necessária. E, as características físicas locais e tradicionais da população devem ser levadas em consideração no momento de seleção das espécies. Acreditamos que subsídios podem ser fornecidos por outros órgãos, para que as autoridades locais responsáveis pelo paisagismo e arborização das áreas públicas possam ser melhor capacitados nesta tarefa. A criação de um manual técnico ou plano diretor para o município, visando o planejamento do plantio e manejo adequado das espécies a serem utilizadas é um instrumento útil e necessário, que pode ser utilizado como guia.

Outra ação importante é a contratação de profissionais qualificados da área, por esses órgãos, pois é notória a falta de participação de um técnico (biólogo, ecólogo, agrônomo, engenheiro ambiental, engenheiro florestal) que tenha o conhecimento necessário acerca das espécies para sua correta utilização no processo de arborização da cidade. 


\section{REFERÊNCIAS}

ALENCAR, L. S.; SOUTO P. C.; MOREIRA, F. T. A.; SOUTO, J. S.; BORGES, C. H. A. Inventário quali-quantitativo da arborização urbana em São João do Rio do Peixe - PB. Agropecuária Científica no Semiárido, Patos, v. 10, n. 2, p. 117-124, 2014.

ALVARES, C. A.; STAPE, J. L.; SENTELHAS, P. C.; GONÇALVES, J. L. M.; SPAROVEK, G. Köppen's climate classification map for Brazil. Meteorologische Zeitschrift, v. 22, n. 6, p. 711728, 2013.

APG IV. An update of the Angiosperm Phylogeny Group classification for the orders and families of flowering plants: APG IV. Botanical Journal of the Linnean Society, 181: 1-20, 2016.

BFG. Growing knowledge: an overview of Seed Plant diversity in Brazil. Rodriguésia, v. 66, n. 4, p. 1085-1113, 2015.

BAStOS, F. E. A.; CAMARGO, S. S.; MENEGUZZI, A.; KRETZSCHMAR, A. A.; RUFATO, L. Levantamento florístico e características das espécies em praças públicas em Lages-SC. Revista da Sociedade Brasileira de Arborização Urbana, Piracicaba, v. 11, n. 1, p. 34-42, 2016.

BATISTA, F. A.; CHAVES, T. P.; FELISMINO, D. C.; DANTAS, I. C. Inventário quali-quantitativo da arborização urbana na cidade de Remígio, Paraíba. Revista de Biologia e Farmácia, Campina Grande , v. 9, n. 1, p. 70-83, 2013.

BEZERRA, C. S.; COSTA, J. M. O.; SILVA, A. B. Levantamento florístico e comparação qualiquantitativa da arborização em áreas verdes públicas da cidade de Monteiro - PB. Enciclopedia Biosfera, Goiânia, v. 13, n. 24, p. 650-660, 2016.

BELTRÃO, B. A.; MORAIS, F.; MASCARENHAS, J. C.; MIRANDA, J. L. F.; JUNIOR, L. C. S.; MENDES, V. A. Projeto cadastro de fontes de abastecimento por água subterrânea: diagnóstico do município de Tuparetama, estado de Pernambuco. Recife: CPRM/PRODEEM, 2005. 26p.

CAMAÑO, J. D. Z.; BARROSO, R. F.; SOUTO, P. C.; SOUTO, J. S. Levantamento e diversidade da arborização urbana de Santa Helena, no semiárido da Paraíba. Agropecuária Científica no Semiárido, Patos , v. 11, n. 4, p. 54-62, 2015.

CARVALHO MARIA, T. R. B.; BIONDI, D.; BROBOWSKI, R. Inventário florístico qualiquantitativo das vias púbicas de Itanhaém - SP. Revista da Sociedade Brasileira de Arborização Urbana, Piracicaba, v. 11, n. 4, p. 79-97, 2016.

DANTAS, A. R.; GOMES, E. M. C.; PINHEIRO, A. P. Diagnóstico florístico da praça Floriano Peixoto na cidade de Macapá, Amapá. Revista da Sociedade Brasileira de Arborização Urbana, Piracicaba, v. 11, n. 4, p. 32-46, 2016.

DE ANGELIS, B.; LOBODA, C. R. Áreas verdes públicas urbanas: Conceitos, usos e funções. Ambiciência, Guarapuava, v. 1, n. 1, p. 125-139, 2005. 
INSTITUTO BRASILEIRO DE GEOGRAFIA E ESTATÍSTICA (IBGE). Manual Técnico da Vegetação Brasileira. Rio de Janeiro: IBGE, 2012. 274p.

LUCENA, J. N.; SOUTO, P. C.; CAMAÑO, J. D. Z.; SOUTO, J. S.; SOUTO, L. S. Arborização em canteiros centrais na cidade de Patos, Paraíba. Revista Verde de Agroecologia e Desenvolvimento Sustentável, Pombal, v. 10, n. 4, p. 20-26, 2015.

LUNDGREN, W. J. C.; SILVA, L. F.; ALMEIDA, A. Q. Influência das espécies exóticas arbóreas urbanas na área de cobertura da cidade de Serra Talhada - Pe. Revista da Sociedade Brasileira de Arborização Urbana, Piracicaba, v. 8, n. 3, p. 96-107, 2013.

MARTO, G.B.T.; BARRICHELO, L.E.G.; SILVA FILHO, D.F.; MULLER, P.H. Arborização Urbana. 2006. Disponível em: <http://www.infobibos.com/Artigos/ArborizacaoUrbana/ ArborizacaoUrbana.htm> Acesso em: 18 jan. 2017.

MILANO, M.; DALCIN, E. Arborização de vias públicas. Rio de Janeiro: LIGHT, 2000. 226p.

PERIOTTO, F.; PITUCO, M. M.; HELMANN, A. C.; SANTOS, T. O.; BORTOLOTTI, S. L. Análise da arborização urbana no município de Medianeira, Paraná. Revista da Sociedade Brasileira de Arborização Urbana, Piracicaba, v. 11, n. 2, p. 59-74, 2016.

RODOLFO JUNIOR, F.; MELO, R. R.; CUNHA, T. A.; STANGERLIN, D. M. Análise da arborização urbana em bairros da cidade de Pombal no estado da Paraíba. Revista da Sociedade Brasileira de Arborização Urbana, Piracicaba, v. 3, n. 4, p. 3-19, 2008.

SHANNON, C. E.; WEAVER, W. The mathematical theory of communication. Urbana: University of Illinois Press, 1964. 125p.

SILVA, A. G. Arborização urbana em cidades de pequeno porte: avaliação quantitativa e qualitativa. Viçosa, 2000. 150f. Dissertação (Mestrado em Ciências Florestais) - Universidade Federal de Viçosa, Viçosa, 2000.

SOUSA, R. D. C.; AGUIAR, O. D.; SILVA, L.; SILVA, L.; MARRA, R. Avaliação qualiquantitativa da arborização na praça Agostinho Nohama, bairro Lauzane Paulista, São PauloSP. Revista da Sociedade Brasileira de Arborização Urbana, Piracicaba, v. 9, n. 1, p. 92107, 2014.

SOUZA, A. R. C.; ROBAINA, A. D.; PEITER, M. X.; FERRAZ, R. C.; SCHUWAB, N. T.; SOUZA, G. R. C.; PINTO, L. M. Identificação das espécies ornamentais nocivas na arborização urbana de Santiago/RS. Revista da Sociedade Brasileira de Arborização Urbana, Piracicaba, v. 6, n. 2, p. 44-56, 2011.

TOLEDO, F. S.; SANTOS, D. G. Espaços livres de construção. Revista da Sociedade Brasileira de Arborização Urbana, Piracicaba, v. 3, n. 1, p. 73-91, 2008.

ZILLER, S. R.; ZENNI, R. D.; DECHOUM, M. S. Espécies exóticas invasoras na arborização urbana: problemas e soluções. In: CONGRESSO BRASILEIRO DE ARBORIZACAO URBANA, 2007, Vitória. Anais do XI Congresso Brasileiro de Arborização Urbana, Vitória - ES: SBAU, 2007. p. 2-18. 